\title{
ENHANCING SIMULATION EDUCATION WITH A VIRTUAL PRESENTATION TOOL
}

\author{
David He \\ Pat Banerjee \\ Department of Mechanical and Industrial Engineering \\ $2039 \mathrm{ERF}, \mathrm{M} / \mathrm{C} 251$ \\ University of Illinois-Chicago \\ Chicago, IL 60607, U.S.A.
}

\begin{abstract}
This paper describes a research plan to address the undergraduate learning challenges encountered when teaching an introductory simulation course in Industrial Engineering programs. It outlines the implementation tasks of the research methodology, an evaluation plan, and one direction for future work.
\end{abstract}

\section{INTRODUCTION}

The growth of simulation courses at both undergraduate and graduate levels has been observed for more than ten years (Jacobson and Morrice 1994). Forgionne (1983) and Harpell et al. (1989) reported that simulation ranks second in utilization (behind "statistical analysis" only) among eight tools in a survey of large corporations. The value and usage of simulation have since increased due to improvements in both computing power and simulation software (Banks 2001). Computer simulation courses have been taught in engineering schools, business schools, and computer science departments in academic institutions worldwide (Altiok et al. 2001; Chwif and Barretto 2001; Stahl 2000). Traditionally, simulation course in an industrial engineering program is taught with concepts being explained in the class by the instructor and the understanding of these concepts and the basic skills being developed by students through exercises and projects outside the class. The assumption in teaching the course is that students already have a sound grounding in the theoretical foundation of probability and statistics and they have enough application domain knowledge allowing them to move quickly into applications. This has not necessarily been the case. As a result, the students have to spend a lot of time at the early stage of the learning process in understanding the basic simulation concepts and the basic use of the simulation tools, which leaves important application issues uncovered or the application topics. At the end of the semester, the students may feel exhausted after spending too much time in learning how the simulation tool functions without devel- oping a real interest in simulation applications. This may limit the options of adding certain advanced topics such as the design of algorithmic optimization procedures for largescale solution spaces. If these topics need to be covered in advanced courses such as "Plant Layout and Materials Handling", "Production Planning and Inventory Control", "Advanced Simulation", and "Virtual Automation" then certain topics in the advanced classes have to be eliminated.

Over the past several years in teaching the simulation course, we have observed that a significant number of students in the class have very little knowledge of application domains. Students with more knowledge about the application problems generally are more enthusiastic about the subject, have a better performance in the class, and tend to be more creative especially in simulation projects. Among the feedbacks collected from students at the end of each semester, the things students complain about the most are the textbooks and little help they can get from the textbooks. The issues we are facing in teaching the simulation course are not only local but also nationwide. To identify persistent issues in simulation education, Nance (200) compares the results of two simulation education surveys in the $1974-76$ timeframe with the results of a 1997 simulation education workshop (Rogers 1997). The results of the comparison indicate that application domain knowledge is vital to a successful study in simulation and an academic background in science or engineering is essential. As clearly indicated in a report on a recent panel on education in simulation (Altiok et al. 2001), the main problem in teaching simulation in academia is how to select varied simulation-related topics into a one-semester course in view of the knowledge the educator wishes to impact to the students. To do so, the educator must factor in the students' skill set.

In summary, application domain knowledge is needed for students to succeed in a simulation course. The challenge is how to efficiently and effectively present and incorporate the application domain knowledge as needed into learning simulation.

We conceptualize that instruction with a virtual teaching and learning environment will provide an efficient and 
effective approach to this subject. A virtual reality tutoring toolkit will aid in diminishing the instruction time period, facilitate and enhance the learning curve of the students, enhance students' understanding of modeling and simulation concepts, and stimulate students' interests in applying simulation techniques to solve real industrial problems.

Towards this end, we plan on developing a virtual reality tutoring toolkit for teaching Industrial Systems Simulation course using a virtual presentation tool. This tutoring toolkit provides a virtual teaching and learning environment that supports the presentation of "real world" simulation problems and solutions in 3-dimentional (3-D), interactive, and animated virtual worlds (which can be easily built by a novice!). The toolkit will contain a group of five pilot modules focusing on five different simulation approaches to problem solving. Each of the five modules will be developed with a real application problem solved by a specific simulation approach. We will use the tutoring toolkit to help students visualize the real industrial systems to be analyzed and simulation solutions to be developed. As opposed to traditional, text-oriented problem or system description in most of the textbooks, a 3-D virtual world has the advantage that most of the system states (like assembly line station, production floor, inventory storage, and etc.) are intrinsic in a "natural" way. These modules will illustrate actual problems found in industry that are related to the material covered in this course. Students see the system state and how it changes over time. Also, 3-D worlds seem to encourage exploration in creating variants of existing worlds and making novel worlds of their own. Another advantage of the tutoring toolkit is that teaching modules can be easily plugged in based on the needs of the instructors. Students can use it to develop their own simulation project presentations.

\section{OBJECTIVES AND EXPECTED OUTCOMES}

The overall goal of our research is to strengthen and enhance student simulation skills as well as to provide students sufficient "real-world" simulation application experience to improve their performance. This is accomplished through the creation of a virtual reality tutoring toolkit using a virtual presentation tool. Three primary objectives are defined as follows:

- Objective 1: Creating the virtual reality tutoring toolkit;

- Objective 2: Using and integrating the virtual reality tutoring toolkit into the simulation course;

- Objective 3: Assessing and refining the pilot research results and products.

The expected outcomes relating to the aforementioned objectives of this project are:

1. an improved learning environment for undergraduate students enrolled in the simulation course;
2. the integration of a suite of technological tools into the simulation course;

3. higher levels of transfer of knowledge from theoretical engineering courses to applied problem solving courses where the theory is applied; and

4. higher levels of learning among students in their perceived understanding of course material.

\section{METHODOLOGY}

Much research has reported on the effectiveness of new teaching approaches using various information technologies. For example, multimedia presentation methods garner favorable responses from educators as well as students. They can make the material more interesting and facilitate the visualization of concepts and examples. Sung et al. (1998) described how multimedia enhances physics lab teaching. Supporting evidence is presented in an article in Mechanical Engineering in which a multimedia approach enhances the effectiveness of learning mechanical-event simulation software (Anonymous 1998). The need for the modern-day simulation teaching to emphasize applications and "real" problems is well documented. Standridge (2000) discussed the application of the case based approach to simulation instruction. Case studies show promise in providing link between methods and their applications. Properly constructed cases provide a "metaphor" for real engineering problems and allow students to "simulate" the role of practicing engineer or manager (1984). Kuo and Deuermeyer (1998) pointed out that the focus of effective modern curriculum should be on the application of the tools rather than the development of the mechanics of the tools. Buzacott (1984) suggested that the Industrial Engineering discipline as a whole should be focused on applications rather than theory. Kuo (2000) indicated that the undergraduate curriculum of industrial engineering programs should be focused on and responsive to industry needs. Indeed, feedback from our own Industrial Engineering assessment processes developed under ABET 2000 criteria show the same. Industry, present students, and alumni desire more focus on simulation applications using advanced technological tools applied to real world problems. In a discussion on the use of cases in engineering education, Richards et al. (1995) concluded that cases need to be combined with other two pedagogical approaches (lectures and homework sets) to create a learning experience appropriate for technology intensive disciplines.

The implementation tasks of the research methodology are outlined next.

\subsection{Creating the Virtual Reality Tutoring Toolkit}

The virtual presentation tool to be used in this work is VisualWorld $^{\mathrm{TM}}$ Presenter (IVRI 2004). The software simulates a virtual classroom and gives user the ability to build and edit an "avatar", which acts as user's virtual presence in the classroom. The user can select an avatar to perform the 
presentation along with several variables to control the avatar's speaking voice. Image files such as PowerPoint slides and JEPG files, videos, and voice files can be easily loaded into the virtual classroom. 3-D objects created by available virtual reality technologies such as VRML and X3D can be easily inserted into the virtual classroom. The VisualWord $^{\mathrm{TM}}$ Presenter presentation can be recorded as a movie that can be viewed on any PC through the Internet. VisualWord $^{\mathrm{TM}}$ Presenter is a virtual presentation tool developed at IVRI under the direction of Pat Banerjee, the co-author of this paper (see $<$ http: //www. ivri. com $>$ for more details). The virtual reality tutoring toolkit will contain five modules with each corresponding to a real manufacturing application problem that simulation addresses. Each module contains one or more learning themes that are important for developing necessary simulation skills, for example, input analysis, model building, and output analysis. Each module will consist of three major components: problem description, step-by-step simulation solution development, and final solution presentation. The description of the application problem in each module will be constructed using videos, photo images, PowerPoint slides, or 3-D models. The step-by-step simulation solution development will be realized using Arena (Kelton et al. 2002; Altiok and Melamed 2001). In order for students to "play with" the simulation models, a user-interface will be developed for each simulation model using Visual Basic ${ }^{\circledR}$ Applications (VBA). The user-interface provides the students with the ability to make limited changes so that certain data required by the simulation model can be input by the students. The presentation of the simulation solution will be constructed in a similar way as the problem description. The virtual reality presentation will provide students a vivid image of the real application problem. For example, in a scene of a virtual classroom shown in Figure 1, the "instructor" is demonstrating the operations of a packaging room with a snapshot of the packaging room shown on the screen and two 3-D models on the lecture room floor. Depending on the needs of the presentation, the 3-D objects can be rotated, resized, and relocated anywhere in the virtual classroom (see Figure 2).

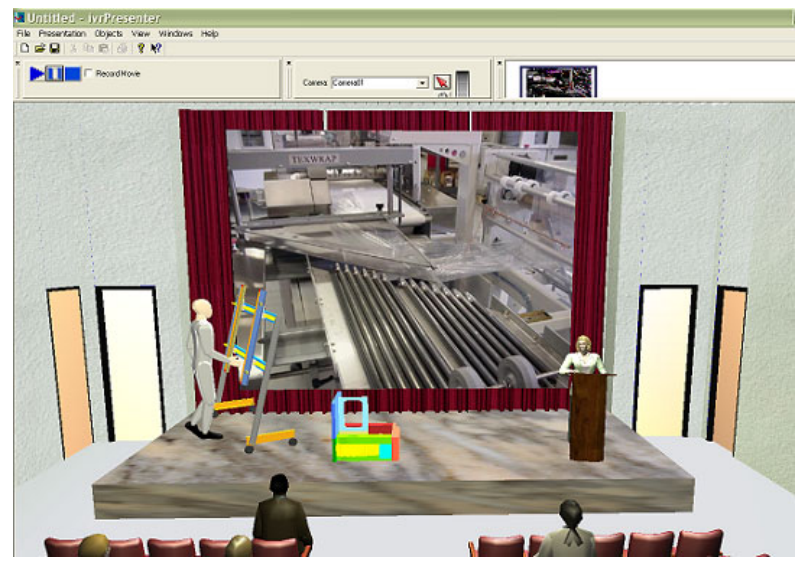

Figure 1: Scene\#1 of a Virtual Classroom

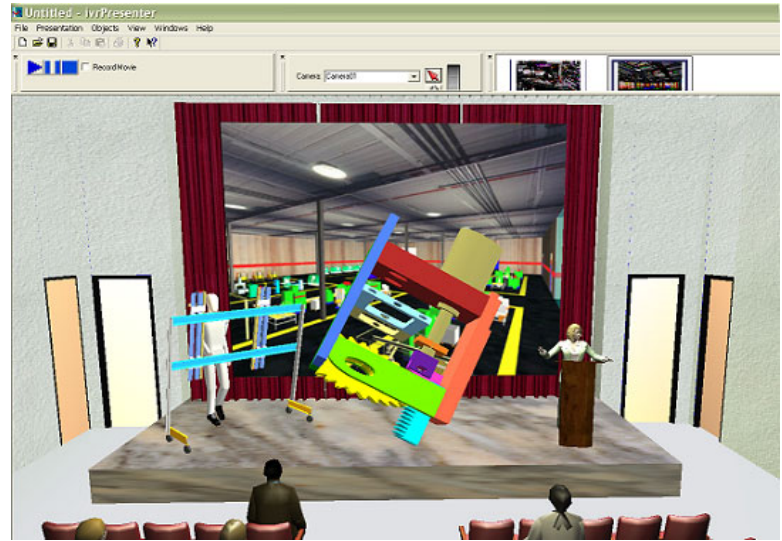

Figure 2: Scene\#2 of a Virtual Classroom

After the five modules have been created into the tutoring toolkit, it will be copied into DVD/CDs and distributed to students in the simulation class.

Note that the three components in each module can be loaded independently into the tutoring toolkit by VisualWorld $^{\mathrm{TM}}$ Presenter. Therefore, the tutoring toolkits can be customized to fit different needs of the instructors and the students. For example, if the simulation course is taught with ProModel rather than Arena, then the simulation solution developed can be realized using ProModel. The problem description component can also be modified or more contents can be added easily with VisualWorld ${ }^{\mathrm{TM}}$ Presenter to fit different teaching and learning needs.

Currently there is no other virtual reality tool like VisualWorld $^{\mathrm{TM}}$ Presenter with which a novice can create a virtual classroom presentation easily. For example, Chover et al. (2002) report a multi-user virtual classroom application using VRML 2.0 and DeepMatrix System $<$ http: //www.geometrek. com>. However, building such a virtual application normally requires expertise in virtual reality programming. We believe that VisualWorld $^{\mathrm{TM}}$ Presenter provides certain advantages for achieving the objectives of the projects:

- A virtual classroom presentation can be created more easily by VisualWorld $^{\mathrm{TM}}$ Presenter. Two unique features make it distinct: (1) automatically converts a PowerPoint presentation into a virtual classroom presentation; (2) any virtual classroom presentation can be easily recorded as a movie.

- Due to its ease of use, the tutoring toolkit can be easily modified to fit different teaching purpose and audiences.

\subsection{Assessing and Refining the Pilot Research Results and Products}

One of the key factors required for this research to be successful will be a fair and objective assessment of the virtual reality tutoring toolkit as well as feedback from four evaluator groups. An evaluation plan is described in Section 4. 


\section{EVALUATION PLAN}

To measure and assess whether the expected outcomes of this project have been achieved, a well-developed evaluation plan focusing on validated constructs and metrics has been formulated to judge the impact of the research. This plan incorporates the validated assessment methods of (Chwif and Barretto 2001; Lewis and Seymour, 2004; Slater 2004), statistical techniques, and program evaluation standards in establishing the universal principles of utility, feasibility, propriety, and accuracy.

\subsection{The Constituents}

In particular, the evaluation of this work will be conducted by 4 distinct groups: the students, industrial representatives, faculty from other institutions, and the authors.

The student evaluators of this work will consist of those that are enrolled in the simulation course. This group will consist of students enrolled in the baseline class and those in the treatment class where the new curriculum including the modules will be introduced. The baseline class evaluations will be used as a control group to measure learning outcomes with a traditional teaching approach. These results will be compared with the treatment class students to measure various areas where statistically valid differences exist between the responses of the two groups.

The industrial evaluators of this work will consist of industrial contacts from those industries participating in this work. Each contact will be involved with the development of their respective modules, but will be asked to evaluate all modules upon completion. They will numerically score various aspects of the tutoring toolkit as well as provide qualitative feedback.

The academic evaluators of our research work will consist of professors who have instructed the simulation course at their respective institutions several times. They will be closely involved with the development of this set of test modules and will give solicited input on the content of such. Upon completion, they will also be asked to numerically score all modules as well as provide qualitative feedback. Peer review is a widely accepted technique for examining the content, construct and criterion validity of instructional materials (American Educational Research Association 1999).

\subsection{Evaluation of the Outcomes}

The evaluation of the five outcomes of the research is described briefly next.

(1) Outcome 1: an improved learning environment for undergraduate students enrolled in highly theoretical courses, and Outcome 4: higher levels of learning among students in their perceived understanding of course material.

- Metrics to measure outcomes: These metrics consist of quantified measures of the perceived use- fulness, fairness, enjoyment, and reasonableness of the pilot modules by the students. Metrics measuring learning include grades, performance evaluation (Slater, 2004) of students by the class instructor, and the perceived understanding of the course material by the students.

- Evaluation tools: An attitudinal survey (Lewis and Seymour 2004) will be conducted upon course completion. This anonymous survey will consist of a series of numerically scored questions that address the aforementioned metrics and a short answer section for additional comments. The numerical results will be compared to those collected for a class prior to the incorporation of the modules using statistical techniques for categorical data. Traditional approaches to measuring student learning including individual assignments, test grades and overall class performance of students will also be used as tools. Two surveys have also been identified as potentially being appropriate (Francis 1993; Loyd and Gressard 1996).

(2) Outcome 2: the integration of a suite of technological tools into the simulation course.

- Metrics to measure outcome: Quantified measures and items on student evaluations in both the baseline and treatment group will be used to assess the use of technology in problem solving. In addition, measures of actual technology utilization in the design of the project as well as students' problem solving activities will be documented.

- Evaluation tools: One of the evaluation tools will be the regular course evaluation, another will be the student exit survey from the program.

(3) Outcome 3: higher levels of transferal of knowledge from theoretical engineering courses to applied problemsolving courses where the theory is applied.

- Metrics to measure outcome: This metric consists of a quantified measure of the student's ability to synthesize this material to "real-world" problems outside of those addressed by the pilot modules.

- Evaluation tools: This quantified measure will be established through an in-class 1-hour individual project at the end of the semester. The project will consist of a data set representing a small manufacturing system and various issues/problems related to the topics covered in the class. The students will be asked to model, parameterize, and analyze one of these problems, and to write a brief summary of their findings. This project will be administered to two classes, the baseline class, and the treatment class where the modules will be incorporated. The 
industrial and academic evaluators will evaluate these project summaries jointly through a holistic scoring system. Statistical techniques will then be used to analyze these results.

\section{FUTURE WORK}

The pilot research results and products can be expanded to different departments, courses and universities in the future. In order to do so, the merit of this work will be established through a peer review process: the set of pilot modules will receive a direct and all-inclusive review by the academic evaluators who will numerically score this work based on the objective, content, and reasonableness of such, and will provide a written set of suggested enhancements and modifications. This review will provide qualitative feedback on the overall concept and rationale for this work.

\section{ACKNOWLEDGMENTS}

This work has been supported in part by a subcontract under NIST ATP Cooperative Agreement 70NANB1H3014.

\section{REFERENCES}

Altiok, T., W. D. Kelton, P. L'Ecuyer, B. L. Nelson, B. W. Schmeiser, T. J. Schriber, L. W. Schruben, and J. R. Wilson. 2001. Panel on Education in Simulation: Various Ways Academics Teach Simulation: Are They All Appropriate? In Proceedings of the 2001 Winter Simulation Conference, ed. B. A. Peters, J. S. Smith, D. J. Medeiros, M. W. Rohrer, 1580 - 1591. Piscataway, New Jersey: Institute of Electrical and Electronics Engineers.

Altiok, T., and B. Melamed. 2001. Simulation Modeling and Analysis with Arena. Fairfield, NJ: Cyber Research and Enterprise Technology Solutions.

American Educational Research Association, American Psychological Association \& National Council on Measurement in Education. 1999. Standards for Educational and Psychological Testing, Washington, DC.

Anonymous. 1998. Online Resources. Mechanical Engineering 120(5): 18.

Banks, J. 2001. Panel Session: Education for Simulation Practice - Five Perspectives. In Proceedings of the 2001 Winter Simulation Conference, ed. B. A. Peters, J. S. Smith, D. J. Medeiros, M. W. Rohrer, $1571-$ 1579. Piscataway, New Jersey: Institute of Electrical and Electronics Engineers.

Buzacott, J. 1984. The Future of Industrial Engineering as an Academic Discipline. IIE Transactions 16(1): 35-43.

Chover, M., Ó. Belmonte, I. Remolar, J. Ribelles. 2002. Web-based Virtual Environments for Teaching. Available online via <http://virtual.inesc.pt/ cge $02 /$ pdfs/chover.pdf > [accessed January $31,2004]$.
Chwif, L., and M. R. P. Barretto. 2001. Assessment of Student Preparation for Discrete Event Simulation Courses. In Proceedings of the 2001 Winter Simulation Conference, ed. B. A. Peters, J. S. Smith, D. J. Medeiros, M. W. Rohrer, 1624 - 1631. Piscataway, New Jersey: Institute of Electrical and Electronics Engineers.

Forgionne, G. A. 1983. Corporate Management Science Activities: An Update. Interfaces, 13(3): 20 - 23.

Francis, L. 1993. Attitude toward Computers Scale. Computers and Education 20(3): 251 - 255.

Harpell, J. L., Lane, M. S., and Mansour, A. H. 1989. Operations Research in Practice: A Longitudinal Study. Interfaces 19(3): 65 - 74 .

Jacobson, S. H., and D. M. Morrice. 1994. Teaching Simulation: A Panel Discussion. In Proceedings of the 1994 Winter Simulation Conference, ed. J. D. Tew, S. Mannivannan, D. A. Sadowski, A. F. Seila, 1378 1381. Piscataway, New Jersey: Institute of Electrical and Electronics Engineers.

Kelton, W. D., R. P. Sadowski, and D. A. Sadowski. 2002. Simulation with Arena. $2^{\text {nd }}$ Edition, New York, NY: McGraw-Hill.

Kuo, W. and B. Deuermeyer. 1998. The IE Curriculum Revisited. IIE Solutions. June 1998: 16 - 22.

Kuo, W. 2000. Educational Program for the Industrial Engineer. Maynard's Industrial Engineering Handbook. $5^{\text {th }}$ Edition, New York: Graw-Hill.

Lewis, E. and E. Seymour. 2004. Attitudinal Survey. Fieldtested Learning Assessment Guide, College Level One Team.<http: //www. wcer.wisc.edu/nise/ CLl/flag/cat/attitude/attitudel.htm> [accessed January 31, 2004].

Loyd, B. H., and C. P. Gressard. 1996. Computer Attitude Scale. Journal of Computing Research 15(3): 241 259.

Nance, R. E. 2000. Simulation Education: Past Reflections and Future Directions. In Proceedings of the 2000 Winter Simulation Conference, ed. J. A. Jones, R. R. Barton, K. Kang, P. A. Fishwick, $1595-1601$. Piscataway, New Jersey: Institute of Electrical and Electronics Engineers.

Richards, L. G., M. Gorman, W. T. Scherer, and R. D. Landel. 1995. Promoting Active Learning with Cases and Instructional Modules. Journal of Engineering Education (84)5: 375 - 381 .

Rogers, R. V. 1997. The Consensus from one Workshop: What Makes a Modeling and Simulation Professional? In Proceedings of the 1997 Winter Simulation Conference, ed. S. Andradottir, K. J. Healy, D. H. Withers, and B. L. Nelson, 1375 - 1382. Piscataway, New Jersey: Institute of Electrical and Electronics Engineers.

Slater, T. 2004. Performance Assessment. Field-tested Learning Assessment Guide, College Level One Team, available online via <http://www.wcer.wisc. edu/nise/CLl/flag/cat/perfass/perfas s1.htm $>$ [accessed January 31, 2004]. 
Stahl, I. 2000. How Should We Teach Simulation. In Proceedings of the 2000 Winter Simulation Conference, ed. J. A. Jones, R. R. Barton, K. Kang, P. A. Fishwick, 1602 - 1612. Piscataway, New Jersey: Institute of Electrical and Electronics Engineers.

Standridge, C. R. 2000. Teaching Simulation using Case Studies. In Proceedings of the 2000 Winter Simulation Conference, ed. J. A. Jones, R. R. Barton, K. Kang, P. A. Fishwick, 1630 - 1634. Piscataway, New Jersey: Institute of Electrical and Electronics Engineers.

Sung, R., W. Fadner, and C. Willis. 1998. Computerenhanced Physics Laboratories. Computers in Physics 12(2): $133-137$.

IVRI. 2004. User Manual of VisualWord ${ }^{\mathrm{TM}}$ Presenter, Industrial Virtual Reality, Inc., Chicago, IL.

\section{AUTHOR BIOGRAPHIES}

DAVID HE is an Associate Professor and the Director of the Intelligent Systems Modeling \& Development Lab in the Department of Mechanical \& Industrial Engineering at The University of Illinois-Chicago. He received his Ph.D. in Industrial Engineering from The University of Iowa. His research interests include: manufacturing systems modeling, quality and reliability engineering, and equipment health diagnosis and prognosis. His e-mail address is <davidhe@uic.edu>.

PAT BANERJEE is a Professor and the Director of the Industrial Virtual Reality Institute in the Department of Mechanical \& Industrial Engineering at The University of Illinois-Chicago. He received his Ph.D. in Industrial Engineering from Purdue University. He served as a Department Editor of IIE Transactions and an Associate Editor of IEEE Transactions on Robotics \& Automation. His e-mail address is <banerjee@uic.edu>. 